\title{
Analysis of Uncontrollable Variables to the Performance of Predefined Tasks
}

\author{
Eunghyun Lee ${ }^{1}$, Jinwoo Lee ${ }^{1}$, Jungwan Hong ${ }^{1}$, Younghoon Ko ${ }^{1}$, Yongjin Kwon ${ }^{1}$, Sang C. Park ${ }^{1}$, \\ Jonghoon Lee ${ }^{2}$, Miseon $\mathbf{Y i}^{2}$
}

${ }^{1}$ Department of Industrial Engineering, Ajou University, Suwon, South Korea; ${ }^{2}$ D Agency for Defense Development, South Korea. Email: yk73@ajou.ac.kr

Received 2012

\begin{abstract}
The aim of this research was to investigate the impacts of changing environmental factors on pilots by implementing the effective flight procedure that we found from the previous research. During the experiments, camcorders were used to monitor and analyze the tasks and physical exhaustion of the pilot. NASA-TLX was also used to collect the data of the workload. Through this experiment, we were able to approach the experiment from a different angle regarding the optimal assigned work of the pilot, unlike the previous studies. Also, we were able to find out the impacts of environmental factors on the pilot's workload.
\end{abstract}

Keywords: Helicopter Mission; Task Performance Time; Task Workload; Armed Helicopter

\section{Introduction}

This research has adopted a new working procedure that involves a different kind of helicopter: a side-by-side helicopter. Due to the fact that the optimal weather condition was included, we did not take other external environmental factors, such as the change in visual field or the change in the management of the equipment, into consideration. Therefore, the main purpose of this research is to find to what extent captain pilots/co-pilots are affected by the external environmental factors including Daytime experiment, Nighttime experiment, Bad weather experiment and Solo flight by using the procedure derived from our previous studies.

\section{Experimental Configuration}

\subsection{Applying Our Previous Research}

The side-by-side helicopter enables the captain pilot/copilot to share the same working area and dualize the flight instruments, thus allowing them to share their tasks. Hence, in order to invent a new combination of the task, we divided the working procedure into four different procedures for Experiment 1. Also, in Experiment 2, we developed a new scenario by dividing the working procedure differently from Experiment 1 and analyzed the recorded data including the total amount of time spent to complete the task, lethality, the efficiency of the performance of the pilots, and more. The optimal working pro- cedure developed through this method is shown in Table $\mathbf{1}$ and has been used for this research.

\subsection{Experimental Method}

Due to the fact that this research is mainly focused on measuring the change in the workload of the pilot according to the change in external environmental factors, we constructed four different experimental environment based on the different time of the day and meteorological conditions that can be manipulated by the flight simulator. Daytime experiment, which was also used in the previous studies, was the most basic experimental environment with the least amount of restrictions. Nighttime experi- ment was executed with the use of Night Vision and had more constraints, such as speed limit, due to the difficulties of securing a clear view. Also, to apply the difficulties of securing a clear view because of the fog, we set the visual

Table 1. Table of flight procedure.

\begin{tabular}{ll}
\hline Pilots & Task detail \\
\hline $\begin{array}{l}\text { Captain } \\
\text { Pilot }\end{array}$ & $\begin{array}{l}\text { Main flight/hovering \& return Operate } \\
\text { communications }\end{array}$ \\
Co-Pilot & Operate warning system Detect the threat \\
Common & Evasion flight/Operation of radio \\
\hline
\end{tabular}


range as approximately 3 miles in Bad weather experiment. Lastly, Solo flight had the same environment as daytime experiment; however, we set it as the environment that captain pilot performs the work by himself/ herself without the help of co-pilot.

We applied randomization and 5 repetitions for each experiment, thus performing approximately 20 experiments. Similar to the previous research, the data of the workload of the pilot was gathered by surveying with NASA-TLX, and the total amount of time spent for each task according to the work distribution was recorded with a camcorder. The video clips from the camcorder were also subdivided with the interval of 5 seconds.

The types of experiments are shown below in Table 2, the images of experiments are shown below in Table $\mathbf{3}$ and the image of a night vision is shown below in Figure 1.

Table 2. Types of experiments.

\begin{tabular}{|c|c|c|}
\hline $\begin{array}{c}\text { Types of } \\
\text { experiments }\end{array}$ & Detail & Characteristic \\
\hline Day & $\begin{array}{l}\text { Operation starts at } 12: 00 \\
\text { All clear weather } \\
\text { Flight speed limit } 130 \mathrm{kts}\end{array}$ & \\
\hline Night & $\begin{array}{l}\text { Operation starts at } 24: 00 \\
\text { All clear weather } \\
\text { Flight speed limit } 110 \mathrm{kts}\end{array}$ & $\begin{array}{l}\text { Use Night } \\
\text { Vision }\end{array}$ \\
\hline $\begin{array}{l}\text { Bad } \\
\text { Weather }\end{array}$ & $\begin{array}{l}\text { Operation starts at } 12: 00 \\
\text { Visual range } 3 \text { miles } \\
\text { Flight speed limit } 100 \mathrm{kts}\end{array}$ & \\
\hline Solo flight & Same as day experiment & \\
\hline
\end{tabular}

Table 3. Images of experiment.

\begin{tabular}{c}
$\begin{array}{c}\text { Types of } \\
\text { experiments }\end{array}$ \\
\hline Images of experiment \\
\hline Night \\
Bad \\
Weather \\
Solo flight
\end{tabular}

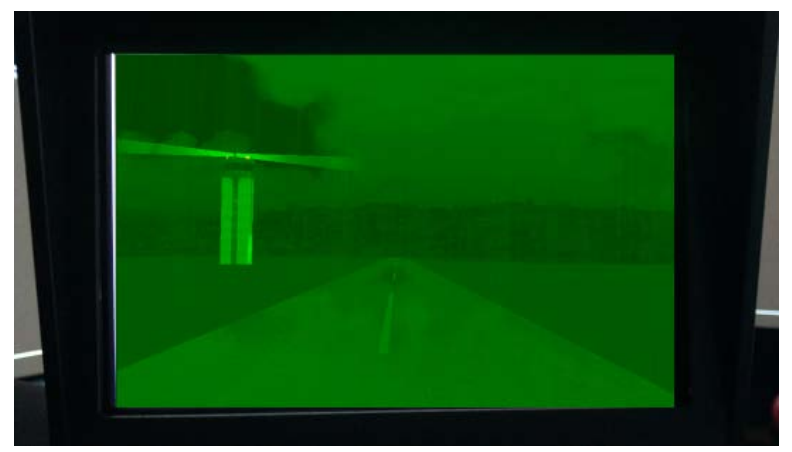

Figure 1. Image of the night vision in TADS.

\subsection{Scenario Composition}

The appropriate scenario has to be composed to increase the efficiency of measuring the workload varied by environmental factors. The scenario consists of the randomized location of the enemy encampment which is accompanied by 4 targets ( 3 buildings and 1 tank). The helicopter that took off at the assigned starting point enters the operational area by contour flying. It then goes to the location of reconnaissance, confirms the target, and completes the change-over. The helicopter moves to the first enemy base and attack. The helicopter operates survival gears and evasion flight. After completing the task and retreating from the operational area, as the helicopter switches back to normal flying and lands on the returning point, then the scenario ends.

\section{Data Analysis}

Setting the reliability as 95\% and using Minitab 16 and the ANOVA (Analysis of variance) in every analysis, we examined the significance of the change in the workload of the pilot according to external environmental factors. Also, we used the method of the Time \& Motion Study to analyze the video clips recorded by the camcorder. The camcorder was placed and secured on the location where it can observe the motion of the captain pilot/copilot and the battlefront at the same time. The recorded video clips were subdivided into the intervals of $5 \mathrm{sec}$ onds and used to analyze the actions of captain pilot/copilot for each task.

\subsection{Analysis of Mission Run-Time}

Setting the standard for dividing the amount of time was quite important to verify the significance of the time required for each mission according to the different types of experiments. The missions required to enact the scenario are shown below in Table 4.

Intervals where the pilot experienced a huge change of action were more subdivided and intervals where the pilot experienced a trivial change of action were combined. The data of captain pilot in the four experiments were 
analyzed and the data of co-pilot was not analyzed in the last experiment where he/she is assumed to be out. Each section was carefully numbered and analyzed with the method of the ANOVA. The first characteristic of this data is that there is a point that cannot be analyzed with the significance test. For these unanalyzable points, we set the duration time. The analysis indicated that the only difference is the flight time between varying weather conditions. Other mission tasks appear to be not different, even though the weather changes according to our experimental procedures.

\subsection{Mission Success Rate}

We did not analyze the mission success rate due to the fact that all of the cases had $100 \%$ of success rate in our previous studies. In other words, regardless of the environment, the pilot is able to complete the mission even though there might be a difference of the amount of time spent and workload. We believe that it occurred due to the difference of the level of difficulty of the missions caused by the limitation of the simulation.

\subsection{Analysis of Captain Pilot/Co-pilot's TLX Data}

By using the method of ANOVA, we analyzed the TLX scores of captain pilot/co-pilot's and investigated which experiment has the lowest workload. The following table shows the p-values. The Statistical significance test of two pilot's TLX data is shown below in Table 5.

Table 4. Mission procedure.

\begin{tabular}{|c|c|}
\hline Mission & Detail \\
\hline Flight to operation area & Move to a reconnaissance position \\
\hline $\begin{array}{l}\text { Lodgment of reconnaissance } \\
\text { position }\end{array}$ & Target searching \& Hovering \\
\hline Detect target & Detect the target \& Identify \\
\hline Evasion flight & $\begin{array}{l}\text { Conduct evasion flight in the event of } \\
\text { threat }\end{array}$ \\
\hline Operate a defensive system & $\begin{array}{l}\text { Work the defensive system in the event } \\
\text { of continuous threat }\end{array}$ \\
\hline Operate a comm. & Work the communications system \\
\hline Check the gauges & Check the condition of instruments \\
\hline Return to base & $\begin{array}{l}\text { After completing the task, the helicopter } \\
\text { back to the base }\end{array}$ \\
\hline
\end{tabular}

Table 5. Statistical significance test of two pilot's TLX data.

\begin{tabular}{ccccccc}
\hline \multirow{2}{*}{$\begin{array}{c}\text { TLX } \\
\text { subsection }\end{array}$} & \multicolumn{3}{c}{ Captain pilot } & \multicolumn{4}{c}{ Co-pilot } \\
\cline { 2 - 7 } & p-value & criteria & result & p-value & criteria & result \\
\hline Mental & 0 & $<=0.05$ & $\circ$ & 0 & $<=0.05$ & $\circ$ \\
Physical & 0 & $<=0.05$ & $\circ$ & 0.216 & $>0.05$ & $\times$ \\
Temporal & 0 & $<=0.05$ & $\circ$ & 0 & $<=0.05$ & $\circ$ \\
Own & 0.004 & $<=0.05$ & $\circ$ & 0.002 & $<=0.05$ & $\circ$ \\
Performance & & & & & & \\
Effort & 0 & $<=0.05$ & $\circ$ & 0.001 & $<=0.05$ & $\circ$ \\
Frustration & 0 & $<=0.05$ & $\circ$ & 0 & $<=0.05$ & $\circ$ \\
\hline
\end{tabular}

Since the data of captain pilot are all statistically significant, we have come to a conclusion that captain pilot is affected by external environmental factors. The order in increasing workload is daytime experiment, solo flight, nighttime experiment, and bad weather experiment. Since there is no physical category for the data of co-pilot, we found out that there is the difference of workload according to external environmental factors in other categories. The order in increasing workload is daytime experiment, bad weather experiment, and nighttime experiment .

\section{Analysis Results}

The reason for the manifest significance of the duration of captain pilot is the speed limit because the helicopter is flying the same amount of distance with the lower velocity. Also, we believe that the reason for the insignificance is that even though we set the enemy encampment, it is impossible for the helicopter to stop at the same exact point and implement the Hovering for every experiment. Contrary to captain pilot, since it is more difficult to clearly differentiate his/her action and there is less limits of movement than that of captain pilot, co-pilot had a tendency to vary more in terms of the time spend to complete the mission. Also, due to the fact that most of the missions of co-pilot accompanied those of captain pilot, when the duration was relatively longer, co-pilot tended to take more time detecting and discerning the target. In terms of the analysis of workload with the use of TLX, since captain pilot had to complete difficult tasks at the same point, he/she had to pay more attention to find the target. We can clearly see that captain pilot has more workload when piloting in the night time using Night Vision and having more limited left-and-right visual field than when piloting after the rain and having a limited visual range. Also, co-pilot has more workload after the rain than in the night time because it is more arduous to detect the enemy and attack with missiles when he/she has a limited visual range than 
when he/she has a narrow angle of visual field.

\section{Conclusion}

Through the experiments, we could see that both captain pilot/co-pilot is under more pressure when external environmental factors are involved. Considering the fact that the mission capability of flight is important even with external environmental factors, such as after the rain or in the night time, it is necessary to install attacking and defensing system based on automation and radio system based on network in the newly developed helicopters to increase the mission capability. In order to enhance the strengths and improve the weaknesses, more research on the development of tactical air employment is recommended.

\section{Acknowledgements}

This work was supported by the Basic Science Research Program through the National Research Foundation of Korea (NRF) funded by the Ministry of Education, Science and Technology (Grant No. 2010-0012517). This work was supported by the Agency for Defense Development (ADD). This paper was also partially supported by the Ajou University Research Fund. The authors wish to express sincere gratitude for the financial support. We also appreciate Ms. Jeongwon Lee for her help with the English translation as well as the editing of our manuscript.

\section{REFERENCES}

[1] Kim Ki-Choel, Lee Jong-Sun, “A Study on the Pilot Workload Analysis in Flight Phases using the Flight Simulator," Journal of Korean Institute of industrial engineerings, Vol. 11, 2001, pp. 227-230.

[2] Woo-Sub Oh, Sung-Woo Kim, Choi Ie-Na, Jin-Suk Jang, "A Study on the System Concept of KHP Mission Equipment Package,” Journal of The Korean Society for
Aeronautical and Space Sciences, Vol. 2, 2005, pp. 1100-1103.

[3] Suk-Joon Yoon, “Airplane R\&D simulator,” Journal of The Korean Society for Aeronautical and Space Sciences, Vol. 30, 2002, pp. 150-162.

[4] Jae-Moon Lee, Chi-Young Jung, Jae-Yeong Lee, “The Combat Effectiveness Analysis of Attack Helicopter Using Simulation and AHP,” Journal of The Korea Society for Simulation, Vol. 19, 2010, pp. 63-70.

[5] Jung Hoon Lee, Jun Ho Kim, Jung Yong Park, Iee Ki An, "Current Status of Civil-Military Dual Use Helicopter Development Focusing on Conversion Case from Civil to Military Helicopter," Journal of The Korean Society for Aeronautical and Space Sciences Conference,2011, pp. 1783-7886.

[6] Jun-Woo Lee, Sang-Won Chae, Chil-Gee Lee, "Development of Panel Part in Flight Simulator based on PC," Journal of The Korea Society for Simulation, Vol. 10, 2001, pp. 31-39.

[7] Sunh-Yun Choi, Sang-won Chae, Young-Sin Han, Chil Gee Lee, "3D Flight Simulator for Education of Flying Tactics," Journal of The Korea Society for Simulation, Vol. 12,2002, pp. 1-11.

[8] Tomas Schnell, Yong-Jin Kwon, Sohel Merchant, "Improved flight technical performance in flight decks equipped with synthetic vision information system displays”, The international Journal of Aviation psychology, Vol. 14, No. 1, 2004, p. 79-102.

[9] Jung-Hoon Lee, Byeong-Hee Chang, Hwang In-Hee, "Current Status of Civil-Military Dual Use Helicopter Development - Focusing on Conversion Case from Military to Civil Helicopter", Current industrial and Technological Trends in Aerospace, Vol. 7, 2009, pp 32-42.

[10] Kang Byeong-Kil, "Development of a Pilot Workload Prediction Program using TAWL (Task Analysis / Workload) Methodology,” Master's Thesis, Gyeongsang National University, Jinju, 2010.

[11] Sung-Ho Choi, Yeon-Chul Choi, Yoeng-Hoek Lee(2007), A Study on Situation Awareness of Helicopter Pilot, Ph.D. thesis, Korea Aerospace University, Seoul, 2007. 